\title{
The Multifaceted Use of a Written Artifact in Student Supervision
}

\author{
Gunilla Jansson \\ Department of Scandinavian Languages, Stockholm University, 10691 Stockholm, Sweden \\ Correspondence should be addressed to Gunilla Jansson, gunilla.jansson@nordiska.su.se
}

Received 3 November 2010; Accepted 29 March 2011

Academic Editor: Miriam David

Copyright () 2011 Gunilla Jansson. This is an open access article distributed under the Creative Commons Attribution License, which permits unrestricted use, distribution, and reproduction in any medium, provided the original work is properly cited.

\begin{abstract}
This article explores the use of a written artifact, an assessment form encompassing a checklist with health care terms, in supervised nurse student-patient interactions during assessment interviews in a Swedish hospital ward. The students were doing their clinical practice and were in their first year of a three-year nursing degree. Even though the students are not in charge of the situation, they are expected to perform a professional task for which they lack adequate skills. As demonstrated, the use of the assessment form provided a useful way for the participants to manage specific tasks in an apprenticeship context, such as regulating affect display, demonstrating uptake of the patient's concerns and staging the interview as an exercise. For this article, three excerpts have been selected from history-taking sequences, when the patient's previous illness history is created. The analysis illustrates the affordances provided by the assessment form to handle perspective shifts, when the patient departs from a general pattern of unelaborated answers and offers a window into his/her concerns. Importantly, however, the students' feedback talk with the nurse preceptor offers evidence that the artifact also constrains their forms of action in the practice of gathering assessment data. The article argues for ward-level practices that socialize students into reflective ways of using the artifact.
\end{abstract}

\section{Introduction}

The present paper is concerned with the deployment of a written artifact, a paper document encompassing a checklist with health care terms (in this article also called "assessment form/proforma" and "assessment sheet"), within specific courses of action in tutored student nurse-patient interactions. The students are taking part in nursing assessment interviews in a hospital ward in Sweden and are supervised by their nurse preceptor.

The health assessment process is described in the nursing literature as an important area of nursing work that offers opportunities to develop a partnership with the patient [1$3]$. Also Candlin $[4,5]$ points to the assessment of the patient's health needs as an important nursing activity, but emphasizes at the same time that a trusting relationship is a prerequisite for encouraging patients to disclose essential information during the assessment process. She points out that the topics within assessment situations relate to the patient's presentation of self and may be emotionally charged. This implies that the nurse has to develop a body of knowledge, or with Bourdieu's [6] terms, a cultural capital, in order to use the institutional instrument, the checklist on the assessment form as a tool for conducting professional discourse and coping with challenging situations.

Being able to develop a trusting relationship in assessment situations where truthful disclosures are apparent is a constitutive element of appropriate nursing care and is crucial for the nurse student's acquisition of professional competence. Candlin [5], in a study of assessment interviews in geriatric nursing care, demonstrates how the ability to elicit rich information based on topics on a nursing assessment proforma is a feature of expertise in nurse-patient discourse. In order to conduct a coherent and therapeutic discourse the nurse has to allow the patient to control the conversation by giving opportunities for digressions from the topics on the proforma. As suggested by Candlin [5, page 179], the expert nurse has greater educational capital [6] on which to draw and can afford to take greater risks. The inexperienced nursing assistant, on the contrary, will not risk failure by the patient to disclose essential information, which may result in an inaccurate assessment. Therefore, she controls the conversation by following the order of topics on the assessment proforma defined by the institution. Or to put it in another way, she is driven by the instrument employed. The expert nurse on the other hand possesses the required 
knowledge and resources to master the tool as a trigger for communication, where multiple topics are addressed from different perspectives.

There is a burgeoning body of research known as workplace studies concerned with technology in action and the ways in which tools and artifacts, ranging from paper documents to complex multimedia systems, feature in conduct and interaction in organizational environments (e.g., [7-12]). These studies have had an important bearing on our understanding of how tools come to exist in practice. They have contributed to our understanding of how professional practice relies upon and is constituted through material artifacts. People in ordinary everyday circumstances use tools and technologies, objects, and artifacts to accomplish social action and interaction. Health care is no exception. Nurses routinely write and read patient records and other documents in their daily work. The admission process is a good illustration of how technology is incorporated into the health care encounter.

Heath et al. [13] point to the disregard in sociological research of the ways in which technical tools and artifacts are used and involved in everyday health care practice. During recent years a number of studies addressing this issue have begun to appear (e.g., [14]). Given the longstanding interest in interpersonal communication in health care the field is well placed to examine the ways in which material resources, tools, and technologies feature in the social interactional performance of clinical activities. Such research might "contribute to our understanding of the ways in which professional practice relies upon, and is constituted through, material artifacts such as medical records, pieces of paper and complex information systems" [13, page 89]. Similarly, Heath and Hindmarsh [15, page 2] highlight the significance of social interaction for an emergent culture and for the organization of everyday activities that people routinely accomplish in their daily work.

In a number of papers Jones [16-18] attempts finegrained analysis of registered nurses' interaction with patients during the admission process into hospital. Through a detailed analysis of question/answer sequences, he demonstrates how the nurses' reading and writing in the assessment document appears at times to limit the patient's voice and restrict opportunities for patient participation. Topics discussed during admission closely follow the layout of the admission document, and patient-initiated expansions during the interview are most often curtailed. Jones [18, page 919] warns against a simplistic and naive reading of the data, one which overestimates the paper documents' power to control the actions of others. He argues for an alternative consideration of the use of technology, which focuses not only on the paper document but also the practitioners who use them and how they learn to use and then apply their understanding of the technology to their daily practice. Similarly, Heath [19] in his study of medical consultations points to many difficulties in using the medical record during the consultation and warns for an unreflective use of the records. Being engaged in reading and writing the records whilst the patient is speaking may not assist the development of a trustful relationship. At the same time he demonstrates how the participants may benefit from the artifact as an interactional resource.

Nursing literature and policy documents in Sweden as well as in other western countries exhort students and practitioners to encourage the patient to be involved in the needs identification process and work through scenarios which enable patient to be self-determining in the decision-making process $[4,20]$. Similarly, there is a growing emphasis in primary health care on the importance of a therapeutic relationship to the management of diverse complaints, including psychosocial problems. However, this process requires the patient to disclose information that may be considered embarrassing and face threatening both to the patient and the inexperienced student. A discoursal style, in which the patient is allowed to talk rather than be guided into talking, may generate communication about emotionally charged topics. To handle such situations demands experience and skills on the part of the practitioner. When disclosing information the patient recognizes the educational capital of the nurse [4], but what discoursal strategies are used by the patient, when he/she is exposed to an inexperienced student? Moreover, the presence of the nurse preceptor imbues the scenario with a strongly asymmetrical master-apprentice relationship that defines the situation and impacts on the discoursal choices made by the interlocutors.

By investigating how an artifact is actually used and made sense of in interaction, the present study seeks to address the issue of socializing novice students into a complex nursing practice. It deals with a complex multiparty environment in nurse students' clinical practice studies in a hospital ward. The setting is framed by master-apprentice relations, where students, although they are not in charge of the situation, are expected to perform a professional task in interactions with patients. More generally, by drawing attention to socially organized practices through which the artifact is used in supervised nurse student-patient interactions, the study seeks to enhance our understanding of what mundane technology such as the paper document does in practice.

\section{Earlier Research on Student Nurse-Patient Interaction}

Little research has been done on student nurse-patient interaction and tutored interaction in particular. Few studies have attempted fine-grained analysis of how interactional features are negotiated sequentially in situ by interactants, when students perform institutional tasks with patients. As indicated by the prior research reviewed below, there is a lack of research into how students are socialized into different professional activities during their clinical practice studies and how they apply their understanding of patient communication in practice. For this literature review, which is far from exhaustive, a couple of related studies have been selected for discussion. Both these studies deal with data gathered from student nurse-patient interaction in assessment interviews. Although none of these studies address issues concerning the use of tools and objects to accomplish social action, they deal with related issues, such 
as the complexity of bridging the gap between theory and practice and exposing novice students to real patients.

A number of studies deal with trainee nurses' therapeutic communication skills and investigate the effects of using standardized and simulated patients as compared to traditional methods such as random encounters with patients in clinical environment observed by faculty (e.g., $[21,22])$. Methodologically, most of these studies are based on data from students' self-reports and faculty's appraisal of interpersonal skills. They do not pay attention to sequential organization and the communicative function of skills, such as, for example, use of open questions.

One of the few studies in the literature that pay attention to the dynamics of interaction is Thomassen's [23, 24] investigation of videotaped student-patient interviews in both nurse and medical students' clinical practice studies at a university in Norway. Whereas the nurse students have a detailed checklist, the trainee doctors have an illusive abstract set of guidelines. One of Thomassen's main findings deals with the difference between the interactional complexity in these two settings. The setting for the interviews in the medical programme is described as complex with the participants having to manage hybridity and shifts between contexts, while the intake interviews in the nursing programme are found to be far less complex as an activity type. Thomassen criticizes exposure of undergraduate medical students to encounters with real patients at an early stage of their education. It may be, she argues, that the participants came to the encounter with conflicting expectations. Using nurse students in intake interviews she regards on the other hand as unproblematic. Both the student nurses and the patient were oriented to the institutional task in the intake interviews, the completion of the checklist. In one of the analyzed transcripts [23, page 134], the patient active engagement in the completion of the institutional task is shown by his suggestion of a formulation for use in the patient record. Moreover, the students were often seen to reformulate health care topics into social "chitchat" and were not prepared to take up the patients' medical concerns. Thomassen [23, page 157] refers this phenomenon to the nursing curricula, where the students are prompted to engage the other in the interview and develop a trusting relationship with the patient.

Another study which conveys a picture of the interaction in situ between nursing students and patients is Jones' [25]. Jones deals with the gap between the patient-centred ideology promoted in textbooks and best-practice guidelines and the ward-level policy that simplifies the nursing assessment to a routinized task. He touches here on an issue related to the present study, namely, the impact of mundane technology on everyday practices at ward level. Jones found that studentpatient interaction during assessment interviews was shaped by the institutional task that needed to be completed, that is, the assessment document. Selected excerpts from the audiorecorded data demonstrate how the bureaucratically inspired interview style of talk adopted by the students imposes restrictions on patients' possible mode of involvement. The interview format, where the nurse asks the questions and the patient answers, is an efficient speech exchange system for the completion of the patient assessment. As Jones [25, page 2305] proposes, it does not fit with the ethos of patient-centred interaction expressed in the nursing literature and promoted in undergraduate nursing curricula. He concludes that students have difficulty in transferring the principles of patient-centred communication from the classroom into their own interaction with patients and recommends the use of empirical data as a resource in teaching undergraduates interpersonal skills. As can be seen from the transcripts presented in the paper, the interaction is frequently punctuated by the student's reading and writing in the paper document. However, Jones does not comment on how the object comes into play within the developing course of action, for example, on how the patient's conduct is susceptible to the student's use of the paper document. His main interest lies in patient participation and how the technology affects the nurse-patient interaction.

Nevertheless, although studies on nursing student-patient interaction show that students' encounters with institutional tasks in clinical environments, such as, for example, collecting data from patients in interviews, involve many complexities, we know surprisingly little about the interactional organization of the practices employed and the interplay of talk, bodily conduct, and material artifacts in such settings. Although it is evident from the transcripts in the studies reviewed above that the paper document is a potentially relevant feature in the interaction, the authors do not address the ways in which the artifact becomes relevant to courses of action.

\section{Artifacts, Mediated Action, and Embodiment}

Theoretically, the present study is grounded in a dialogical and sociocultural tradition that proposes all human sensemaking to be action based, interactive, and contextual. More specifically, it builds upon recent work on workplace practice that has sought to bring different strands of research closer to each other (e.g., $[7,9,15,26,27])$. Goodwin, for example, views artifacts as inscribed into traditions of use, embodying prior human experiences and shaped by a sociocultural history. Also Heath [19] argues for an understanding of human action as built through the simultaneous deployment of multiple resources. Social action is accomplished through a variety of multimodal resources, and not solely talk. Talk gains its meaning as a social action in conjunction with bodily conduct and material resources surrounding it. Bodily conduct and the material environment play a crucial part in the production of social action [28], [15, page 11]. People invoke objects and tools in their immediate environment when they accomplish social action and when they make sense of the actions of others.

Goodwin claims in several places (e.g., [26, page 1489]) that a theory of action must consider both the details of language use and "the way in which the social, cultural, material and sequential structure of the environment where action occurs figure into its organization." Not only human action but also cognition is a socially situated process. Therefore, he argues that a primordial site for the study of 
not only social action but also cognition is when people talk within situated interaction attending to bodily conduct and a range of different kinds of semiotic resources provided by the material environment. These semiotic materials, including objects and artifacts, are culturally defined spaces, such as maps, diagrams, coding schemes, and colour charts.

As stated by Goodwin [26, page 1491] in one of his articles, the emphasis on cognition as a public, social, and reflexively situated process embedded within a historically shaped material world is consistent with a sociocultural approach to mind which takes its framework from the writings of Vygotsky [29]. (In the writings of sociocultural scholars, and particularly in Wertsch [30-32], the term "mind" is used rather than "cognition." Wertsch [30, page, 14-15] discusses this in one of his early writings, where he argues that the use of the term "mind" rather than "cognition" reflects a desire to integrate a wide range of psychosocial phenomena, like, e.g., cognition, cognitive development, but also other aspects of human life such as self, affect, and emotion, as well as human thinking and sense-making in general.), A basic theme that runs through Vygotsky's writings is the claim that human action is mediated by tools and signs and that it cannot be separated from the cultural context in which it occurs. Scholars working within a Neo-Vygotskian perspective [3032] also stress the mediated, historically shaped character of cognition and social action. Hutchins [33] has demonstrated how a cognitive system extends to a group of individuals as well as a set of complex tools. Thibault [34, page 151] talks about cognition as "distributed all along the extended loop of body-brain systems, artifacts, semiotic resources and the material world." Wertsch $[30,31]$ expands Vygotsky's sociocultural approach by developing an account of semiotic mediation, which serves to link the sociocultural setting with the individual mind. Based on Vygotsky's (e.g., [29]) writings on the parallels between social and individual planes, he outlines a framework for tool-based mediation that recognizes the cultural and institutional situatedness of mind. This theoretical construct connects psychosocial processes to sociocultural setting in a more distinct way that had been done before, a goal that Vygotsky did not attain in his empirical research.

One of the central themes, drawn from Vygotsky's works, outlined by Wertsch (e.g., [32]), is the concept of artifacts. A central aspect associated with the term is materiality. Artifacts are semiotic phenomena that can be touched and manipulated. Items such as maps, diagrams, graphs, schemes, drawings, writings, and symbol systems have a clear materiality in that they are physical objects. They are shaped by a sociocultural history in the sense that they continue to exist after the humans who used them have disappeared. Another central theme associated with artifacts is the concept of affordances. Artifacts are inscribed with meaning potentials, affordances [35], which provide opportunities, methods, for use. When exposed to these affordances in interactional contexts, the human agent may perceive, select, realize, and act on them.

Linell [36, pages 345-350], based on the work of Bakhtin (cf. [37]), Rommetveit [38], and Vygotsky [29], has outlined a framework for a dialogical conceptualization of artifacts. He stresses the actual use of affordances. Physical objects become artifacts, or with another Vygotskian term cultural tools or mediational means [30, 32] with special affordances, when they are attended to and realized by users. A dialogical theory regards affordances as dynamic, relational phenomena. Wertsch [32] too points out the relational power of mediational means. By using them we may reduce complex tasks, for example, a mathematical problem, to a series of concrete procedures. For example, the assessment proforma is assigned local and situated meaning when practitioners and learners integrate it with their activities and when they use it creatively. With a concept borrowed from NeoVygotskian framework, they appropriate the tool and make it their own [32, pages 53-54], [36]. A crucial claim made by Wertsch in several places (e.g., [30,31, page 37]) is that cultural tools are the product of necessary factors derived from the institutional setting, such as financial factors, the constraints of time, and efficiency demands, and not sociocultural forces. This is proved by the fact that the practitioners who use the tools are often not aware of their power. In this sense, in the words of Wertsch [32, page 29], "we are unreflective, if not ignorant, consumers of a cultural tool."

In recent dialogically inspired work, artifacts have been interpreted as third parties that can be oriented to as interactants (see, e.g., [36]). When artifacts are used by human agents, they can be conceptualized as parts of the extended, distributed mind, extending into body and environment. The institutional form, like, for example, the assessment form in the present study, may in this sense be viewed as a controlling party that guides the interactants' procedures during the institutional encounter. This is in fact also consistent with the view that the assessment proforma governs the speech exchange system, as put forward in the studies by Jones [17, 18, 25] and Candlin [5].

Given that tools gain their cultural meaning through social interaction, researchers have to deal with the practical, indigenous use of the artifacts in everyday circumstances in health care environments. It is when the tool is used in practice that it gains its particular significance. In line with this dialogical conceptualization of artifacts, the present study investigates the procedures employed by the participants in tutored student-patient interactions, encompassing talk, bodily conduct, and tool use. The study directs analytical attention towards hybrid contexts in student supervision in a hospital ward, where working life impinges on educational contexts. It analyzes how a physical object becomes an artifact in a specific context and how it gains special affordances which are attended to by its users. Whereas previous studies, like, for example, Jones' $[17,18,25]$, reveal how artifacts constrain interpersonal communication, the present study seeks to adopt an alternative approach by considering the power provided by the artifact. At the same time this study affords attention to the accomplishment of social action, in and by means of which the artifact gains its particular significance and is inscribed with meanings. 


\section{Method}

Methodologically, the present study adopts conversation analysis's (CA) detailed attention to interactional processes and participation framework explored through participants' orientations on a turn-by-turn basis [39, 40]. (The term "participation framework" is used here in a CA sense, which means that participants organize their talk in concert with each other, continuously displaying to each other their awareness of what activities are in progress (see, e.g., $[19,41])$. Within a sociocultural framework, the term is used in a broader, quite a different sense, and refers to ways of participating and gaining access to activities in a community of practice (see, e.g., [42]).) By attending to the design of talk for its recipients and the integrative use of the admission document with talk and body movement, the study explores the methods used by the participants when coping with the demands imposed by the educational setting. The analysis also borrows from theory on mediated action to incorporate a concern with the affordances provided by a cultural tool and how they are selected and attended to by the participants for carrying out coherent courses of action. The study integrates sequential microanalysis with ethnographic observations and fieldwork, undertaken both in clinical settings in the ward and in teaching environments in college. This enables us to make a fuller analysis of the participants' methods, which are comprehensible only in light of the specific arrangements of student supervision in the ward, and the procedures used by professionals in the local sociocultural setting.

4.1. Setting. The analyses presented in this paper are based on video recordings of and ethnographic fieldwork on supervised nurse student-patient interactions during student nurses' first period of clinical practice studies in a Swedish hospital ward. The first clinical placement falls in the second semester of the nursing degree programme and aims to introduce the students to clinical practice and encourage them to integrate theory with practice (cf. [20]). The course objectives state that the students are expected to be able to demonstrate skills in communicating respectfully with patients and their relatives and in performing and documenting health assessments. Policy documents [3, pages 71 and 87] mention the assessment interview as one of several ways of gathering information and assessing the patient's nursing needs. The nursing curriculum however does not mention this at all. At ward level it is most common to use the formal assessment interview as an opportunity to socialize first-year students into the nursing activity of assessment. In the ward where this study was carried out, first-year students' health assessments were supervised by a nurse preceptor on a regular basis.

4.2. Data and Recordings. The present study is part of a larger investigation of student nurses' socialization into different professional activities during their clinical practice studies $[43,44]$, which has been carried out as three separate studies. (The project "Bilingualism as a resource in students' socialization process in multilingual educational environments" is financed by the Swedish Research Council and is headed by the author, Department of Scandinavian Languages at Stockholm University. Other coworkers in the project are Dr. Helena Bani-Shoraka, Department of Linguistics and Philology at Uppsala University and a Ph.D. student, Olof Poignant, Department of Scandinavian Languages at Stockholm University.) The data include students with different ethnic and linguistic backgrounds. Two of the studies focus specifically on the use of language by bilingual and second language students. The study from which the present paper is drawn focuses mainly on students who have Swedish as their first language, of whom a few are bilinguals with native or near-native language proficiency in Swedish. First- and second-year students' interactions with patients (all patients in the investigation are native Swedes and have Swedish as their first language), nurse preceptors, and college educators during clinical placements in seven different hospital wards were video-recorded. The data in the larger investigation also include observations and records of student supervision and care work in clinical settings and of lessons during the students' theoretical studies, interviews with educators, and video recordings of assessment interviews carried out by registered nurses in the hospital wards where the students underwent their clinical practice studies. The handwritten notes taken during the interview and the nursing documents produced as a result of the interviews were photocopied and anonymized. All these data were collected in order to sketch the overall features of the setting.

The present study focuses on two female nurse students, Lisa and Sarah (all names are fictitious), and their interactions with patients and their nurse preceptor during assessment interviews. These interviews offer one of the first interactions with a health professional during the patients' hospital visit. The data include two video-recorded sessions of two-student nurse-patient interactions (with two different patients), the nurse preceptor's follow-up interaction with the patient, and her subsequent feedback conference with the students immediately after the assessment interview (76 minutes of recordings). The students' notetaking on the assessment sheet as well as the digital record keeping has been collected. The digital nursing documents were written by the nurse preceptor in collaboration with the students.

The study design was approved by the Regional Committee for Research Ethics. Each participant (students, patients, and nurse preceptors) signed a written informed consent prior to the video recordings of the assessment interviews, acknowledging their voluntary participation, knowing that all personal information would be anonymized. Prior to the assessment interviews the nurse responsible for the students' clinical practice asks the patient whether he/she is willing to have an assessment interview with an undergraduate student. The patients' approval was sought prior to the video recordings.

The students were in their first year of a three-year nursing degree, during which they are exposed to a variety of clinical placements and also receive teaching focusing on theories on communicating skills during college weeks. During the data collection the students had spent two weeks in a cardiology ward where they went through their first 
clinical practice studies. None of the students had worked in a clinical setting before, and this was the first time that they carried out an assessment interview. Both students are in their late twenties and have Swedish as their first language (Sarah is bilingual in Swedish and Spanish. She immigrated to Sweden in her early childhood and has native (or at least near-native) proficiency in Swedish.) The nurse preceptor is a registered female nurse in her early forties with about 15 years experience of clinical practice. The patients, both in their late eighties, were scheduled admissions and were admitted to the ward for surgical operation (adjustment of pacemaker).

4.3. The Artifact and Ward-Level Practices. The written artifact used by the participants in the present study is a paper document that functions as a checklist. It is a simplified paper-based version of a computerized assessment template encompassing a list of health care terms, "keywords," for example, "reason for admission", "previous health history", "current treatment", "life style", "breathing", "communicating," and "sleeping." Each ward made its own selection of keywords depending on the medical specialization. Next to the key terms room was provided for the nurse's notes. The professionals in the ward called this document an "assessment form".

The keywords listed on the paper sheet are drawn from an empirically based assessment framework developed by health care researchers and outlined in a national government policy document [3]. The framework is intended to provide language to conceptualize the health care process. The policy document was used as course literature in the nursing programme in which the students taking part in this study were enrolled. In the hospital ward, where the students did their clinical practice, a simplified version of the model, a folder, was stored in the staff room and was used on occasions as a manual for documentation both by professionals and students. The nurse-preceptor used the folder and referred to the keywords in the assessment document template during supervision sessions with the students. The framework is a model for the nurse's documentation in the patient record, and it does not offer any guidelines on aspects of communication or how the assessment interview should be performed. The policy document advocates patient centredness and patient involvement during the assessment process, but avoids offering specific guidance on how the framework should be used in practice (or any other aspects on nursing practice). The keywords are supposed to provide support for the nurse's identification of the patient's nursing needs. They are not meant to restrict the nurse's documentation. The nurse is free to formulate her text, and how the text is structured depends on the individual patient. In the document it is stated that the ideology and the accumulated professional knowledge underlying these keywords have to be implemented at every phase in the nurse's caregiving [3, page 26].

The paper-based checklist was not only used in student supervision. The professionals in the ward used it as well during assessment interviews. Students doing their clinical practice in the ward are instructed to use the checklist.
However, there is no instruction accompanying the form which states how it should be deployed. The practices utilized at ward level are not always in line with, and appear at times even at odds with, the philosophy underpinning the assessment framework in the policy document. The professionals have developed their own situated practices that aid them in managing the recurring task of assessing and documenting patients' care needs. Using a checklist with keywords during the interview is a procedure that has emerged locally, and it is embedded in the practitioners' everyday social practices. It was a strategy invented by the workers themselves, and it was not recommended or even discussed in the nursing curriculum. The printed checklist was used in other wards also, but not in exactly the same way. Since the context of care delivery, constraints of time, and workloads varied between hospital wards where this investigation was conducted, every ward had developed its own practical use of the assessment framework.

A study of video-recorded assessment interviews by professionals in the ward [45] indicates that the nurse's discoursal style and the extent of the influence of the patient's voice on the interaction vary between contexts because of several factors, such as time constraints. Many of the interviews exhibit restricted environments in terms of patient participation. At times the nurses follow the order of keywords listed on the document rather rigidly, which has implications for the patient's voice within the interaction. There are however cases when the assessment document functions as an informal prompt sheet and when the professional allows digressions and provides scope for the patient's voice. Certainly, using this paper sheet with its list of predefined topics during the assessment interview helped the nurses to complete the task in their hectic work in the ward. The professionals at ward level have developed their own local strategies that help them to manage the paper work as a routine task.

\section{Three Contexts for Artifact-Based Participation in History-Taking Sequences}

The complexity of the tutored student nurse-patient interactions is seen from the view of all three participants. The students are novices and participate as apprentices in the practice of assessing patients' nursing needs. They are guided by a more expert member of the community, a nurse preceptor. To use a terminology borrowed from Lave and Wenger's [42] participation framework, the students practice modes of the behaviour of a nurse in apprenticeship contexts. This means that their interactions with patients and more skilled parties in the community, for example, their nurse preceptor involve, at least initially, limited, highly asymmetrical forms of coparticipation. For the sake of security, they are not given legitimacy to perform professional activities without the support of a more skilled practitioner. However, even though they are not in charge of the situation, they are expected to perform the assessment interview, a professional task for which they lack the necessary skills. The patients bring to the meeting their illness histories suffused with troubles 
and concerns, but are often seen in the corpus of studentpatient interaction to restrict their histories and avoid display of affect. Under these circumstances and given this strongly asymmetrical master-apprentice relation, the nurse preceptor has to perform and orient herself to several goals and tasks simultaneously, both care work and instructing students. She has to guarantee that relevant information about the patient's health history is provided for the sake of safety and security. At the same time she has to adapt to the curriculum and provide opportunities for the learning of a professional task.

On the whole, the history-taking in the student-patient dyads is organized into an interview format and is designedly shaped as a restrictive environment for patients' responses. The student and the patient coconstruct a series of questions embodying a checklist dealing with background information. This is described elsewhere in the literature as a general pattern during history-taking in medical interaction [46, 47]. The student's question invites a response in terms of unelaborated facts, a question/answer design that facilitates a movement through the list of questions. However, on some occasions individual patients deviate/depart from this general pattern of unelaborated answers and offer a window into their concerns by elaborating their answers. This paper focuses on instances in the data when such elaborated answers occur and explores the affordances provided by the assessment sheet to handle these perspective shifts. The contexts for these affordances (i.e., the specific tasks managed by the paper document) cluster into three main classes.

(i) Regulating affect display [48] and talk about troubles in the student-patient dyad. The patient shifts from an objective to a personal stance towards the topic at hand. The assessment form provides a method for closing the affective state and facilitates the movement through the list of questions.

(ii) Demonstrating uptake of the patient's concerns. The nurse preceptor, in her follow-up conversation with the patient, proceeds where the student finished and takes up the patient's indexing of affective stance. The assessment form provides a method for referring back to previous assessment topics.

(iii) Staging the interview as an exercise that involves all three participants. The patient comments on the magnitude of the student's writing, and the student asks the nurse preceptor for help with the notetaking. The assessment form provides a method for the participants in the student-patient dyad to talk explicitly about the writing as a practice embedded in the educational setting, thereby departing from their institutional roles as client and interviewer and constructing a locally relevant novice student identity.

For this paper three excerpts, each of which illustrates the contexts above, have been selected from sequences of history-taking, where the patient's previous health history is discussed. The keyword "previous health history" appears as the second keyword under the heading "case history" on the assessment sheet and follows the keyword "reason for admission." Both students stick closely to the sequence of keywords as they appear on the assessment form.

The analysis highlights the role played by the paper document as a tool that functions together with other resources in providing methods for the participants to participate in a complex practice. My claim is that this written artifact should be seen as a cultural tool that has both a mediating and a determining role during the accomplishment of the professional task.

Some background contextual information is in order. For the sake of security, the nurse preceptor is present during the student-patient interview, in which she takes the role of a supervisor without intervening in the interaction. Before the interview she tells the patient that she will add some questions afterwards if needed. When the student has completed the task and closed the interview she leaves the floor to the nurse preceptor, who takes over the conversation with the patient.

5.1. Regulating Affect Display. I will begin by demonstrating how the assessment form is used as a resource for the participants in the student-patient dyad for regulating affective stance and talk about troubles. Affect displays and stance shifts can be indexed at all levels of language, for example, grammar [48], which will be shown below. Before turning to the analysis, the particular circumstances that frame the student-patient interaction will be discussed in the light of some theoretical considerations. This will be done in order to provide a full understanding of the demands imposed by the setting.

The patient in the dyad is suffering from heart problems and is admitted to the ward for adjustment of his pacemaker. Another circumstance of crucial importance is that the patient is suffering from prostate cancer, a diagnosis that he has received recently. In view of the apprentice context, this item of information could be hard to handle for both parties, the novice student and the patient. Sacks [49], in one of his seminal papers, considers the regulation of information exchange with regard to troubles, noting that "for any two parties not any item of such information may be offered to any given other" (ibid. p. 71). In a medical setting however, the exchange of such information about troubles is a recurrent practice in a doctor-patient consultation, for example. In an admission interview like the current case, an inquiry about health history and previous illnesses is not only a highly askable question; it is also a manageable routine question. Sacks [49, page 74] goes on to state that

\footnotetext{
"[any] person feeling lousy and having some trouble as the explanation of feeling lousy, if asked how he is feeling by someone who ought not hear that trouble or hear it now, may control that one's access to that information by avoiding the diagnostic sequence, and the diagnostic sequence is avoided by choosing a term from a subset of other than the subset the monitoring operation comes up with; that is he may lie."
} 
What Sacks states in his argumentation is that the system regulating information exchange above all involves the answerer's, and not a potential asker's, determination of whether a given asker can handle the particular information on personal troubles. The method that the asked has to align to in similar situations, he concludes, is to answer for instance "Ok" or "Fine" and avoid offering an answer likely to generate talk about troubles. Jefferson [50] also focuses on this dual aspect of troubles talk in ordinary conversations. A central feature of troubles talk, he proposes, is a tension between attending to the trouble as a problematic departure from a course of ordinary events and attending to the business as usual in a manageable way (ibid. p. 153).

Although the student-patient interview is an institutional encounter and takes place in an institutional setting, it is at the same time framed by restrictions prescribed by role relationships in the educational setting. Because of this blend between contexts, the patient has to conform to rules that he potentially would not have respected if the asker in the dyad had been an experienced nurse. It is the business of the patient, when asked a personal state question, to determine whether the student can receive and handle the bad news that he has recently received a cancer diagnosis. He has to control his answer by reference to that determination. In the analysis it will be shown how the assessment sheet is used as a resource to manage this process.

In Excerpt 1 the nurse student (Sarah, female, 27 years) and the patient (male, 86 years, admitted for adjustment of pacemaker) are sitting at a table in front of each other in a small consultation room. The nurse preceptor and Lisa, a fellow student, are sitting in a sofa beside the table. The interaction begins two minutes into the assessment interview.

The excerpt begins with the student's reading in the paper document. On line 2 the student introduces the keyword previous health history on the assessment sheet by posing an open-ended question, hur har du mått förut/eller din hälsosituation innan/nu (how have you been feeling up to now/or your health before/now) and reformulates after a 1 second pause, hur har din hälsa sett ut innan (what has your state of health been like earlier?). The response ja den har varit berg å dalbana (well it's been up and down) (line 5) indicates that things are not quite as they should be. On line 7 the patient begins a list where he enumerates chronologically ordered events and problems in his previous health history: his bypass operation in ninety-five and the ensuing problems with his heart. The list format enables the patient to regulate information and monitor affect display. He delivers some affectively neutral items about his health history, and no more than is necessary to fill in the boxes on the assessment form. This strategy in turn helps the student to accomplish the professional task.

During the patient's answer on lines 13-14 there is a shift from an objective to an explanatory and personal stance towards the element of prostate cancer, the second item in a two-part list with medical statements. This communicative stance shift is resolved by use of the Apokoinou method [51, 52]. Syntactically an Apokoinou utterance can be described as two incoherently linked syntactic products or a three-part structure with a central part preceded by an initial part and followed by a final part, where the final part is syntactically and pragmatically parasitic on the immediately previous segment. Prosodically it is produced as a coherent unit, that is, the speaker integrates the final part in the ongoing turn and does not use prosodic cut-offs and/or restarts during the construction process. In the CA literature this phenomenon is described as a conversational resource, that is, a method used to resolve local communicative projects.

In the extract here, the Apokoinou method is used to resolve a communicative perspective shift. From a formal perspective, the patient does a shift between two different syntactic structures that overlap on the central segment à sen e: har jag $(0,4)$ prostatacancer (and then eh: I've got prostate cancer). At this point the turn is brought to a pragmatic and syntactic possible completion. The syntax does not project any continuation, and the action of providing the student with items to fill in the form could also be complete at this point. Prosodically, however, the turn remains open. There is a stress on the last word prostatacancer (prostate cancer) that postpones the syntactic projection of upcoming completion. The verb-initiated final part within the Apokoinou utterance, har jag fått besked om $i(0,5)$ för ett par veckor sen (I was told a couple of weeks ago), provides an explanation of the second item in a two-part list (the heart and the prostate cancer). The patient was informed about the prostate cancer a couple of weeks ago and not about the heart. The heart topic is outlined in the interaction preceding the Apokoinou utterance on lines $7-11$ as a chronicle and not as a newly arisen problem in the patient's health history. The explanatory Apokoinou is produced as a way of highlighting the social aspect of the prostate cancer, that is, that he has recently received the diagnosis, which is probably significant and a preoccupation in the patient's current life situation. The adverb phrase in the final part that focuses on the time aspect, för ett par veckor sen (a couple of weeks ago), is produced during outbreath with a tense and weak voice. Communicatively, the patient shifts stance towards the topic å sen e: har jag $(0,4)$ prostatacancer (and then eh: I've got prostate cancer). The utterance begins with a stance towards the topic as an objective fact, that is, as a medical statement, but then the perspective changes into something that concerns the patient's life world. In this tension between affective neutrality and affective stance, indexed at different levels (grammar and voice quality), the patient only temporarily offers a window into his preoccupations and concerns. This stance shift provides a procedure for constructing a locally relevant patient identity interpretable here as "resigned" and "care-needing."

Continuing the activity of history-taking at this moment might open up the patient's life world and generate questions and responses on medical and social concerns about the prostate cancer. The novice student does not have the professional knowledge required to handle emotional stance and take up complex information that may be transmitted in this kind of patient account. What the patient does in this apprentice context is to provide the student with short medical statements that can be easily written down 
on the assessment sheet, while avoiding emotional display and refraining from substantial off-topic expansions and expositive descriptions of personal experiences. This strategy helps the student to manage the rendering of the patient's history. The information offered by the patient about his prostate cancer is a complex issue, both from a medical and social point of view. This complex issue is transformed into a manageable item, "prostate cancer," that the student fills in the health history box on the assessment form. A comparable strategy is noted by Jones [18] in his study of nurse-patient interviews and by Berg [53] in his study of doctor-patient consultation. They have noted that writing down one-line summaries of complex medical and social issues produces a particular rendering of patients' histories that appear more manageable on paper than when communicated verbally by the patient.

In this case, the paperwork is the focus of both participants. The restriction of the patient's history is achieved collaboratively by the participants through the simultaneous deployment of different multimodal resources encompassing both talk, material object and body movement. The patient arranges his talk to organize the participation framework that makes the student's form-filling task possible. He organizes his talk, the list construction, in concert with the student's reading and writing in the assessment form. When the patient introduces the bypass topic on line 7 the student moves her gaze towards the assessment form placed on the table in front of her where she writes in the health history box "95 bypass". She looks up again when the heart topic is introduced (line 9). After some acknowledging work on lines 10-11 she reorients towards the paperwork and writes "problem with the heart". When the patient goes on with the item list on line 13, he looks away from the student for a short while (the student is still writing at this moment) and shifts orientation in the course of introducing the cancer topic, à sen e: har jag $(0,4)$ prostatacancer (and then eh: I've got prostate cancer). At this moment the student raises her pen from the paper document, lifts her head, and gazes at the patient. In the stance shift, just before the final part of the utterance, har jag fått besked om i $(0,5)$ för ett par veckor sen (I was told a couple of weeks ago), she withdraws her gaze and begins to write. During the proceeding explanatory part of the utterance, the student's gaze is on her notes. The patient orients his gaze towards the paperwork and remains silent during the 5 seconds it takes for the student to write "prostate cancer" in the notes (line 18). The patient is therefore sensitive to the way in which the student reads and writes in the assessment form. On line 19, the patient conforms to what Sacks [49] labels as the rule of lying, when he states that everything is "fine", annars ere väl bra (otherwise things are fine). When the nurse student aligns to this downgrading of affect by rephrasing the patient's answer (line 20), normality is restored.

The main activity that goes on in the excerpt analyzed above is the completion of the form-filling task. In fact, I will argue that filling in the form is carried out in collaboration between the nurse student and the patient. The shared focus on the paper work helps the participants to regulate the exchange of information with regard to troubles and restrict patient histories about medical and social concerns. The student's writing on the assessment form is an effective way of closing down an activity and regulating affect display at a moment when the patient shifts stance towards a topical aspect during transmission of information. The student may in this way have found refuge in the document when the patient raises the topic of cancer.

In the feedback conference with student and nurse preceptor (also video-recorded and transcribed), the handling of the patient's concern about his cancer diagnosis is one of the main topics discussed. The nurse preceptor stresses the importance of exploring what is experienced as problematic by the patient in his current social life world. She also explains for the student that the data gathered in the admission interview form the basis for the assessment of the patient's health and social care needs in the ward and also for documentation of problem areas in the patient record. Cancer is an emotionally loaded word, and it may be that the patient is very sad and upset after having received the diagnosis, she suggests. The student, on the other hand, expresses frustration and accounts for the helplessness she experienced at the moment when the patient told about the cancer diagnosis. It is evidenced in the feedback talk that the student found it extremely hard to cope with the situation and that she did not know how to handle the information disclosed by the patient. She even felt that she bulldozed the patient when she proceeded with the next keyword on the assessment sheet and that she felt that she ought to have stopped here but that she did not know what to say. What she felt most hard to cope with was her pity for the patient and that she definitely judged this an inappropriate emotion to communicate in this particular situation.

The student's own understanding of her conduct is interesting since it confirms the line of reasoning in the analysis. It is a difficult task for the novice student to handle emotions when the patient wants to talk about his troubles and one for which she lacks adequate skills. The reading and writing on the assessment form is an institutionally relevant action, and it provides the student with professional legitimacy. What is written down is given legitimacy. Regulating emotions via the act of reading and writing is therefore accountable by virtue of its institutionality. At the same time the student senses that her possibility of practising the role of a "caring nurse" for use in her future profession is constrained. The assessment form provides an affordance for the student, an interactional resource that both empowers and restricts her action.

5.2. Demonstrating Uptake of the Patient's Concerns. The next sequence to be analyzed is drawn from the nurse preceptor's interaction with the patient. When the student has completed the task, that is, when she has come to the end of the list on the assessment form she concludes by saying to the patient då var vi nog klara med mina frågor (then we are finished with all my questions I think). She then thanks the patient for letting her do the interview and leaves the floor to the nurse preceptor, who takes over the conversation with the patient. The seating is the same as that in Excerpt 1. The student and the patient keep their 


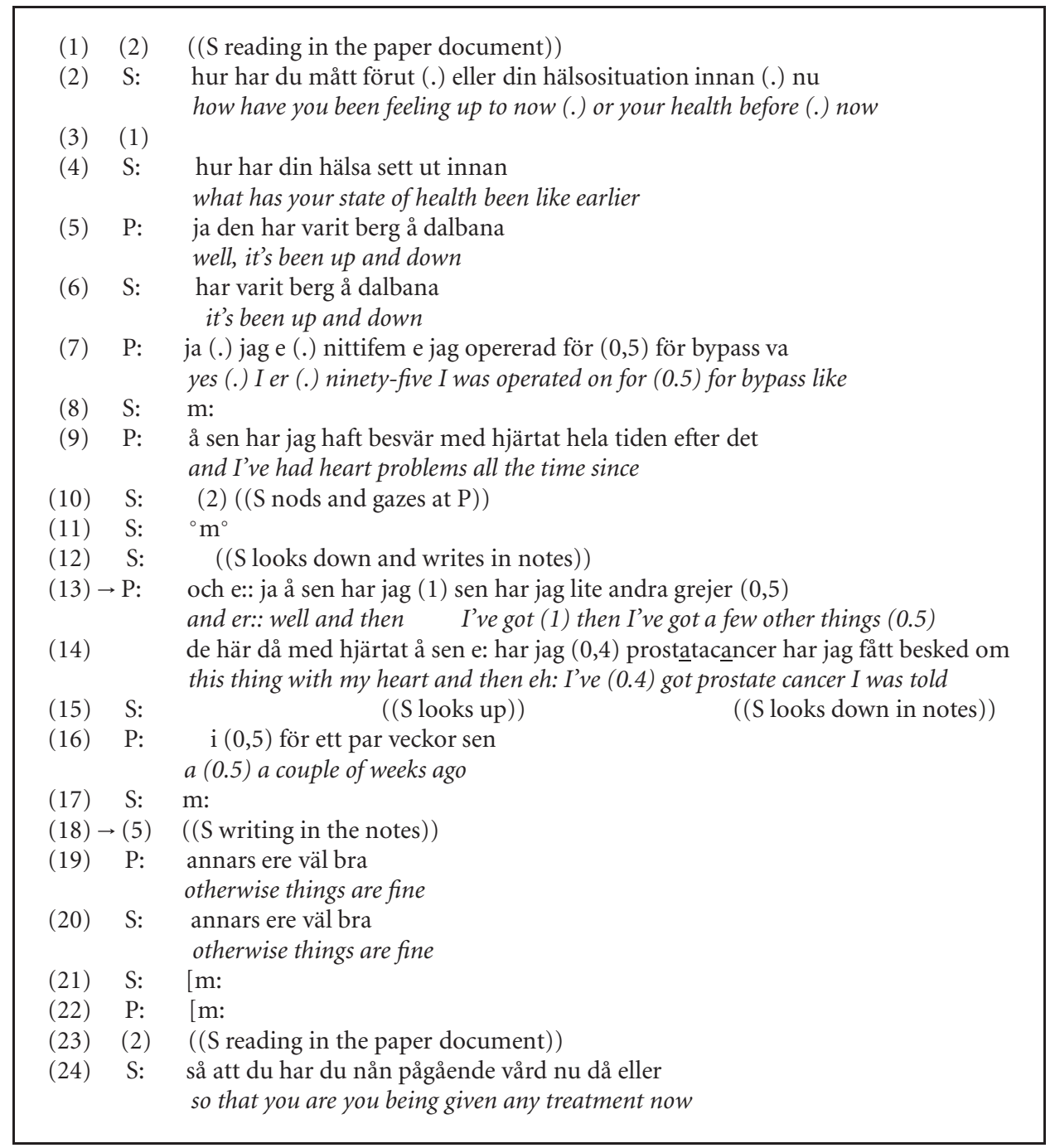

ExCERPT 1: Nurse student-patient interaction. Nurse student (S) and patient (P) sitting in front of each other at a table in a consultation room. Nurse preceptor and Lisa, a fellow student, are sitting in a sofa beside the table. Two minutes into assessment of surgical patient admitted for adjustment of pacemaker.

places at the table opposite each other. The patient turns to the nurse preceptor, who leans forward in the sofa and moves closer to the patient. What the nurse preceptor does in the unfolding conversation is to take over where the student finished. At the same time she demonstrates to the student how the assessment form is used by a professional. There are numerous places in the data (not shown here) where the assessment form is used in a similar way by the nurse preceptor. Whereas the shared focus in the student-patient interaction is on the form-filling task, the main activity in the nurse-patient interaction is uptake of the patient's concerns.

The conversation that unfolds here is a dyad, at least with regard to verbal exchange. However, if one adopts a framework encompassing both talk and embodied practices, the student should also be regarded as an active coparticipant. Even though the student does not take part in the conversation verbally, she plays an active role as an observer in the way she attends to the talk through gaze and bodily conduct. Through head nods, which are offered in particular sequential positions and with varying intensity, she shows endorsement of the nurse preceptor's, and also the patient's, perspectives and stances. In positions when the nurse preceptor encourages and shows approval of the patient, the student nods with higher intensity (see, e.g., line 15). This is what Stivers [54] refers to as social affiliation. Stivers' claim is that nodding during storytelling conveys something different than vocal continuers (ibid. p. 32). The student in the current study claims through her nodding practices to have achieved some measure of understanding of the nurse preceptor's demonstration of uptake. In this blend between contexts, several activities are going on simultaneously, both instruction, learning and nursing care. This hybridity demonstrates the complexity 
of student supervision as a pedagogical practice embedded within the daily routine work in a hospital ward.

The argument presented here is that the use of the assessment form facilitates the nurse preceptor's participation in this complex practice where working life impinges on educational contexts. It is not the artifact as a material resource that can be touched and manipulated that is used here. The student has folded the assessment sheet and put it to one side on the table after the interview. It is another property of the artifact, its sign system, that provides an affordance here. Although the sheet of paper is not used as an interactional resource, it plays a crucial role as a procedure in the nurse preceptor's instruction. The demonstration of uptake is driven by the template for admission framework with its assessment topics, on which the artifact is based. The assessment form provides a method for referring back to previous assessment topics. It enables the nurse preceptor to demonstrate to the student how rich and relevant information is volunteered in nurse-patient interaction. The nurse preceptor demonstrates how a professional allows digressions from the keywords on the sheet. The information disclosed by the patient and written down by the student in the box "previous health history" constitutes a basis for the nurse preceptor's elaborated digression.

In the student-patient interaction, the patient has been guided into talking about the topics on the assessment form. Most of these topics present no problems for the patient. The stance shift in the analyzed history-taking sequence above forms an exception. It is the information disclosed in this stance shift that the nurse preceptor's elaboration in Excerpt 2 builds upon. The nurse preceptor takes up the patient's indexing of affective stance and allows him to talk about his concerns. This move generates troubles talk about side topics related to the patient's heart problems, the surgical operation, and above all the cancer diagnosis. The analysis will include discussion of how this practice is facilitated by the use of the assessment form. Whereas the assessment form was used in the student-patient dyad as a tool for restricting patient history, it is used by the professional as a tool for opening up the patient's life world.

Excerpt 2, follows four minutes into the nurse preceptor's interaction with the patient, after a discussion about the patient's heart problems and issues concerning the surgical operation.

In the sequence preceding the Excerpt 2, the patient's experiences of his heart problems have been discussed. The heart topic was listed as the first item in a two-part list in the student's case history of the patient (see Excerpt 1, line 9). This excerpt begins with a closure of this topic, men annars har jag väl inte nåt speciellt (butotherwise I don't really have anything special to add). In order to restore normality after troubles talk, the patient conforms to the same rule of lying that he adopted in the interaction with the student (see Excerpt 1, line 19). However, the nurse preceptor does not align to this method. Instead she pursues an expansion of the patient's answer to the student. On line 4, she takes up the second item in the two-part list, the prostate cancer, fast de var ju jobbigt de här med din prostata cancer (but it must have been difficult with this prostate cancer you've been told about recently). She affiliates with the patient's affective stance in the Apokoinou utterance in the interaction with the student (see Excerpt 1, line 14). This affiliative move generates a sequence with elaborated troubles talk, where the nurse preceptor demonstrates skilful topic management (cf. [5]), similar to what Jefferson [55] labels as stepwise transition in troubles-telling in mundane conversations. She begins with the cancer topic (line 4), proceeds to urination (line 43 ), a theme that provides opportunity for the patient to introduce another related topic, relevant for the patient's care needs, namely, problems with leakage (line 49). This topic in turn provides a cue for the nurse preceptor's introduction of another theme, namely, the supply of aid and sanitary pads for men (not shown here). So we see how the conversation flows easily from one topic to another enabling the participants to address the cancer topic from different perspectives. This discourse practice, I argue, is supported by the use of the assessment form in the student-patient interaction.

On line 43 the nurse preceptor takes up the patient's urination problems, an issue related to the cancer topic, and information disclosed by the patient (not shown here). In the student-patient interaction, in which an interview approach is adopted, the topic management was determined by the given order of items on the assessment form. The data thus elicited enable the nurse preceptor to refer back to previous topics and take up related topics that have a link with each other. In doing so she creates what Candlin [5, page 183] refers to as comprehensive coherence, where one topic appears to provide a cue for the introduction of another. At the same time this is a demonstration of the discourse practices of expert nursing care. In the subsequent elaboration, the patient supplies details that specify how urination problems impact on his social life world and restrict his abilities, for example, that he cannot manage his hygiene himself (lines 49-55) and that he cannot visit his daughter who lives abroad due to this functional deficit (not shown here).

As demonstrated in Excerpt 2, the participants deploy institutionally relevant ways for indexing their social identities and relations as "care-needing" patient and "caring" nurse. The nurse preceptor's "caring" identity is shaped by the way she frames the interaction as an informal conversation, demonstrated by the latching of utterances and the overlapping utterances as she approves with and aligns to the patient's stances (see, e.g., lines $21-26$ and 3032 ). In fact, this is also what she does on line 4 , when she takes up the patient's problem. The life world narratives on the other hand, charged with affective stances like shame, anxiety, complaint, and embarrassment, provide a method for constructing a locally relevant patient identity. The nursepatient interaction constitutes in this respect a continuation of the stance shift in the student-patient interaction. The patient identity as care-needing that we caught a glimpse of here provides a basis for the nurse preceptor's procedure. It also provides an opportunity for the nurse preceptor to demonstrate for the student how role relationships are shaped in a professional-client encounter. 


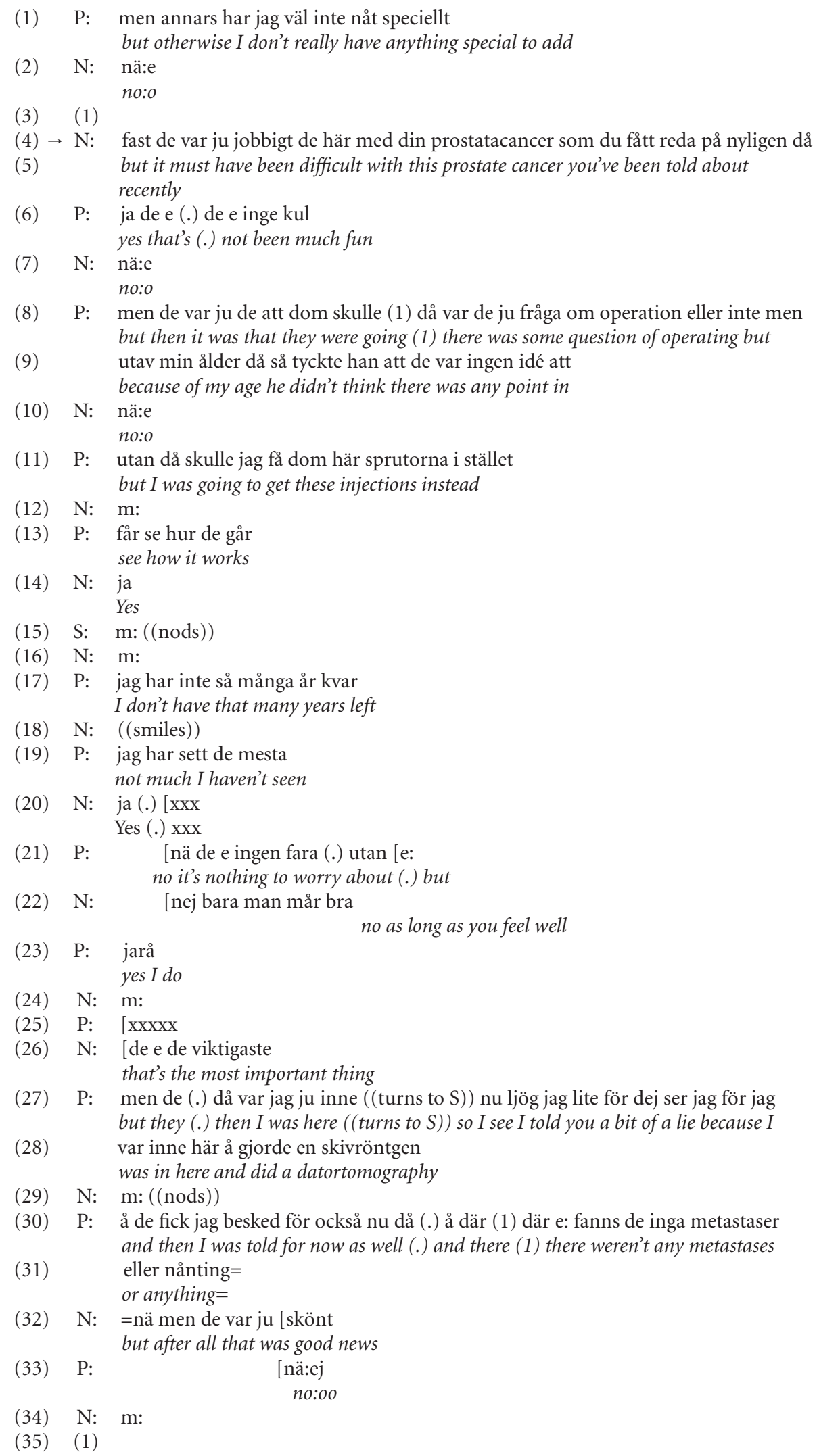




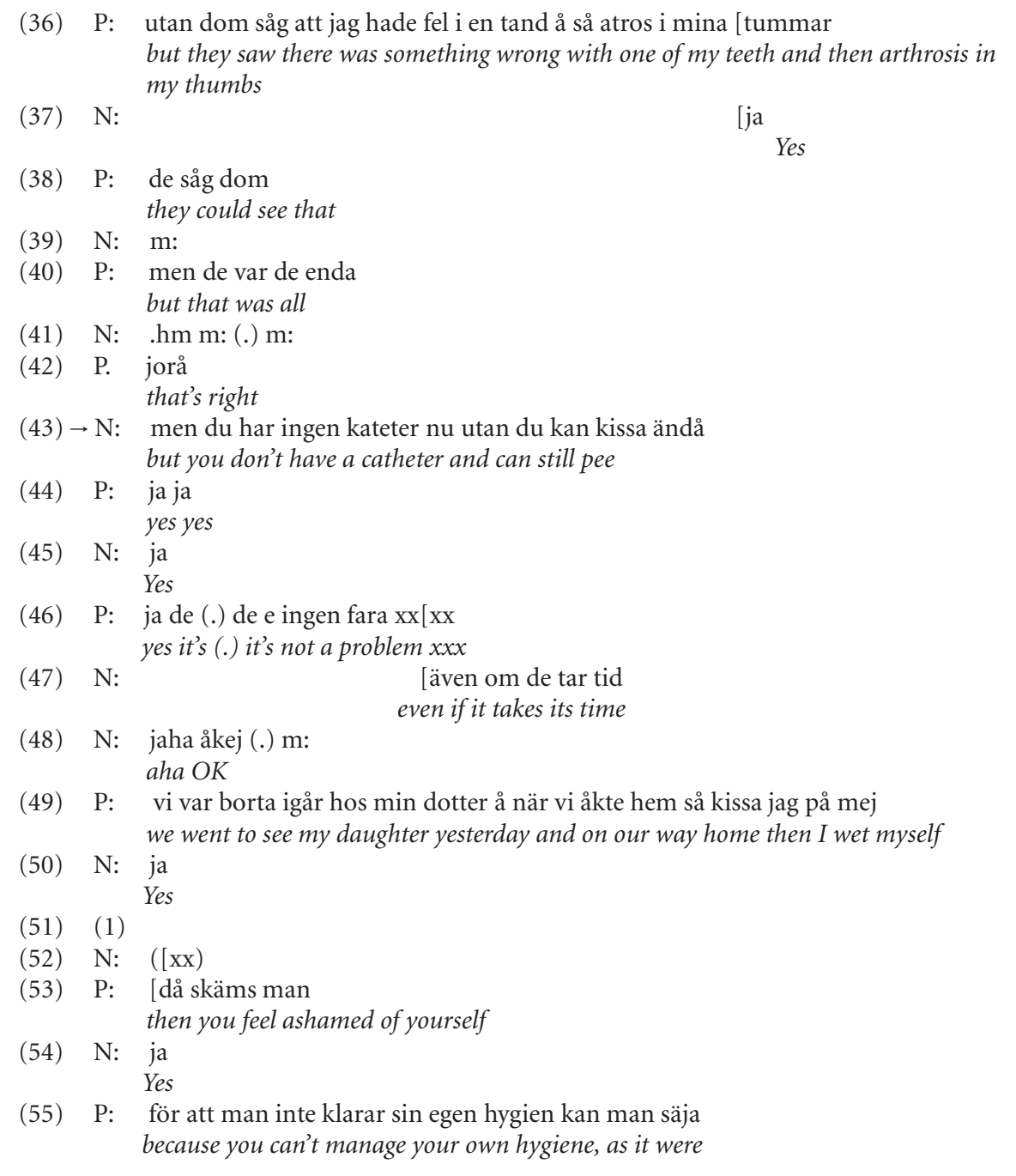

EXCERPT 2: Nurse-patient interaction. Nurse preceptor $(\mathrm{N})$ explores the patient's concerns about the cancer diagnosis. The same participants and seatment as in Excerpt 1. Four minutes into nurse-patient interaction.

5.3. Staging the Interview as an Exercise. The third and last excerpt to be analyzed is drawn from the assessment interview by Sarah's fellow student Lisa, who was sitting in the sofa during Sarah's interview. The participants are sitting in the same consultation room as in Excerpts 1 and 2. The student nurse (Lisa, female, 27 years) and the patient (female, 89 years, admitted for adjustment of pacemaker) are sitting at a table facing each other. This admission interview took place two days after Sarah's. The nurse preceptor is sitting in a sofa beside the table.

This last excerpt illustrates another potential provided by the assessment form. The shared focus on the reading and writing on the document turns the form-filling task into a public activity and stages the interview as an exercise that involves all three participants. This means that the participants talk explicitly about the writing as a practice embedded in the educational context. The interaction begins six minutes into the assessment interview, when the patient's previous medical history is discussed. Excerpt 3 presents the last 25 lines of this discussion. The previous health history topic on the assessment sheet is introduced by the student's question å tidigare vårderfarenhet (.) har du vårdats förut på sjukhus (.) under ditt Iiv (and previous hospital treatment (.) have you been treated in hospital before (.) in your life). The patient, who suffers from a weak heart, has had several falls. She has had hospital treatment on several occasions for fractures in her legs, feet, arms, wrists, knees, and in her hip joints.

Excerpt 3 constitutes the last item in a list construction where the patient enumerates previous fractures and operations in her medical history. In the sequence preceding the extract, the patient accounts for a fracture in her anklejoint related to a fall and hospital treatment of her hip joints related to a heart infarction. The excerpt begins with 


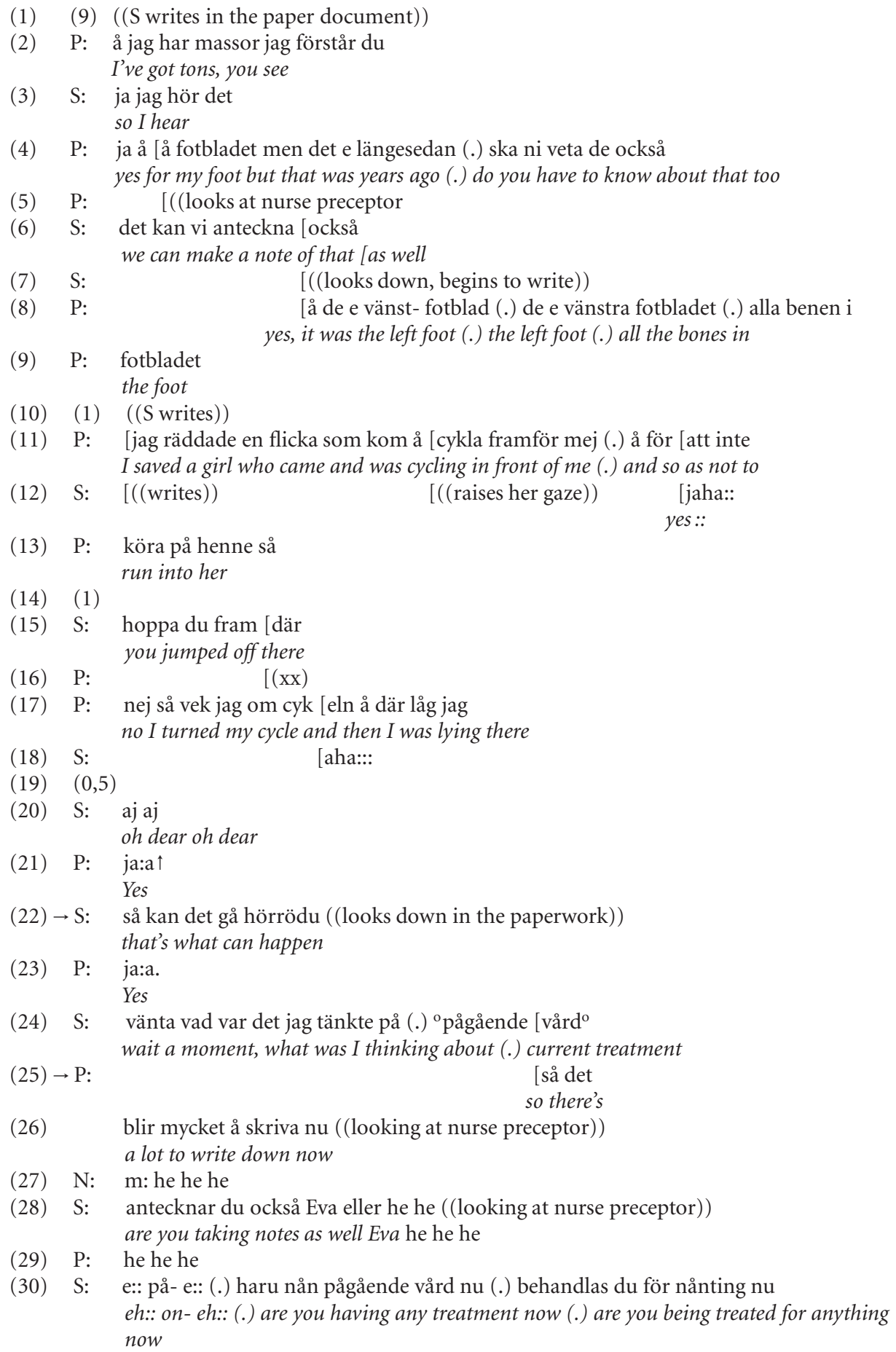

ExCER P 3: Nurse student-patient interaction. Nurse student and patient sitting facing each other at a table in a consultation room. Nurse preceptor sitting in a sofa beside the table. Six minutes into assessment of surgical patient admitted for change of pacemaker battery (P: patient, S: student, and N: nurse preceptor).

the students making notes on the assessment form. While the student is still writing, the patient comments on line 2 jag har massor jag förstår du (I've got tons, you see), indicating that there is more to come. The patient initiates a new topic, the foot, thereby moving on to the next item in the list. Before introducing her story, she glances at the nurse preceptor, asking if this is something they have to know, since it was long ago, ska ni veta de också (do you have to 
know about that too). The patient delivers her story, a bike accident, and the student writes in the notes "the left footall the bones".

To begin with, the patient provides the student with affectively neutral medical items about the foot (lines 4 and 8-9) needed for filling in the previous history box on the assessment form. On line 11, there is a shift from an objective to a personal stance toward the foot item. While the student is still writing "the left foot all the bones" on the assessment form, the patient expands her turn and starts to tell the story of her bike accident. In overlap with the patient's narrative the student raises her gaze from the paperwork. Through the detailed portrayal of the scene, kom å cykla framför mej (came and was cycling in front of me) and och där låg jag (and there I was lying), the patient provides insight to the reported event and to her stance toward the event. In the context of a story these constructions convey a sense of immediacy and exposedness. The conclusion of the story och där låg jag (and then I was lying there) can be said to depict the patient's position as the innocent victim of the inappropriate behaviour of a young girl. The student aligns with the patient by delivering an emphatically loaded acknowledgment token aj aj (oh dear oh dear, line 20). In immediate response, the patient delivers a ja:a $\uparrow$ with rising intonation and gazes at the student as seeking even more endorsement of her position. However, the student does not take up any further aspect of the story's telling. At this moment, when the student has been given access to the patient's life world narrative and explicitly endorsed the patient's position in the story as problematic, she withdraws her gaze. She returns to the paperwork and delivers a sequence closing formulation så kan det gå hörrödu (that's what can happen) that treats the patient's narrative as concluded. In this way reading and writing in the assessment form provides an institutionally relevant method for the student to restore normality. It facilitates movement through the list of questions.

So far the restriction of the patient's history follows the same pattern described in the analysis of the nurse studentpatient interaction in Excerpt 1. The tension between an objective and a personal stance towards the patient's history is managed through the use of the assessment form. In the sequence to follow, lines 25-29, there is a frame shift, when the participants step aside from their institutional roles and make metacomments on the amount that has to be written down. The patient's narrative expansions, one of which we have seen described above, make the writing, and the assessment task, more demanding for the student. This is not only due to the extent of the expansions and the lengthy list of previous treatments. It should also be related to the way in which the elaborated turns create a movement away from the agenda of the student's question. The student therefore has to make a great deal of effort to handle these departures. She has to restore normality in order to move through the list of questions. The lengthy list of items entails more writing, which in turn makes the task more demanding for the student, since she has to handle a great amount of information that has to be documented for the sake of security. To sift the relevant from the irrelevant in the flow of information disclosed in the patient narratives is a difficult task for the untrained student. She carefully writes down all the items in the patient's history on the assessment form. Since there is not enough space in the previous admission box, she uses the margins for her notes.

On line 24 the student looks down at the paper document and strikes her brow, as if she was searching for the next topic on the assessment form. While reading in the document, she says in a low voice vänta vad var det jag tänkte på (.) opågående vård ${ }^{\circ}$ (wait a moment, what was I thinking about (.) current treatments). This move generates a sequence where the writing is not only the participants' shared focus but also becomes a public activity that is explicitly talked about. The patient shifts her gaze to the nurse preceptor and comments on the student's writing, så det blir mycket å skriva nu (so there's a lot to write down now). In overlap with the delivery of the element skriva (write), she makes a quick eyebrow flash, and the nurse preceptor responds immediately with an acknowledgment token and a laugh. At this moment, when several actors are involved in the interaction, the student also shifts her gaze to the nurse preceptor and asks if she is taking notes as well. The patient laughs, as does the student while redirecting her gaze to the paperwork.

What we see in this brief episode in the remaining six lines of the transcript (lines 25-29) is how the strongly asymmetrical master-apprentice role relationship in the educational setting is located within an embodied sequence of action. With both bodies and gaze the patient and the student orient to the nurse preceptor. They build through embodied stance a public framework of mutual orientation. This framework is sustained through the actions of the participants. For instance, the patient's turn at lines 25-26, så det blir mycket å skriva nu (so there's a lot to write down now), is tailored as an action that provides a cue for its interpretation. This brief exchange between the patient and the nurse preceptor sustains a framework for interpreting the talk activity as an exercise staged for the student's training. The student also turns to the nurse preceptor and seeks assistance with the notetaking, antecknar du också Eva (are you taking notes as well Eva), thereby positioning herself as a student. The orientation to the artifact, the assessment form, provides a procedure for the participants in the student-patient dyad to talk explicitly about the writing as an exercise embedded in the educational setting, thereby deviating from their institutional roles as client and interviewer in a professional encounter.

There are numerous sequences (which are not shown here) where the patient departs from her role as a patient and positions herself as the student's helper, placing her in the position of a "little girl" who is doing well her exercise. She makes metacomments on the student's writing, saying, for example, jösses vad du får skriva flicka lilla (heavens, what a lot you have to write, my girl), whereupon she laughs and looks at the nurse preceptor. The student also laughs and looks at the nurse preceptor, responding tur att Eva sitter här också (lucky that Eva's here as well), thereby explicitly negotiating the multilayered frame. At the end of the interview the patient says to 
the student ja du har fått skriva mycket (well you have had to write a lot) and jag tänkte de att du ska jobba hårt (I thought it would be good for you to work hard). The student smiles and responds that this is good for her training, de e bra då får jag öva ordentligt. In overlap with the student's response the patient laughs and glances at the nurse preceptor. In this way the student's training is turned into a publicly witnessed activity that involves both the patient and the nurse preceptor. Both the patient and the student make metacomments on the writing activity, evaluating it as good for the student's training. They get involved in a form of external evaluation of the ongoing exercise. The orientation to the nurse preceptor as a professional authority plays a crucial role in this staging of the talk activity as an exercise, even though she does not take part in the verbal exchange.

In the feedback conference with the student, the nurse preceptor lifts the history sequence analyzed above as an illustration of a fluent and talkative patient: "When you asked her about her previous health history, then you got more than you bargained for, didn't you?" The student laughs and says that her story seemed endless. "I thought she never would stop", she says. The nurse preceptor underscores the importance of retaining the relevant information in similar situations. "She was a talkative woman/then it is difficult to sift the relevant from the irrelevant information and this takes a lot of training," is her comment. So we see how the patient's elaborated turns in this history sequence are pointed out by the nurse preceptor as a demanding context for an untrained student.

\section{Concluding Discussion}

As demonstrated, the integrative use of the assessment form with other modalities provided a useful way for all three participants to manage specific tasks in an apprenticeship context, such as regulating affect display, demonstrating uptake of the patient's concerns, and staging the interview as an exercise. As such, it facilitated the novice student's accomplishment of the professional task.

For the untrained novice student, the assessment situation in a clinical environment is as challenging as for the nonexpert nursing assistant in Candlin's [5] study. She lacks the required body of cultural knowledge, a cultural and educational capital [6], but still she has to perform the assessment interview and overcome the risk of erroneous decisions on the basis of insufficient information. The institutional instrument, the assessment proforma with its institutionally predefined topics, provides a tool that can be used in such circumstances in order to avoid the risk of being misunderstood and losing face.

Here it is important to underscore that the proforma not only provides a tool for the untrained student. Ethnographic fieldwork carried out in the ward indicates that the paper document also aids professionals in managing the recurring task of assessing and documenting patients' care needs [45]. Also Jones (e.g., [18]) in his study of nurses admitting patients into hospital points to similar results.
As Wertsch [32, page 25] has stated, almost all human action is mediated action. Humans rely on cultural tools to carry out actions and solve problems. This also holds true, I argue, for the specific courses of actions carried out in the present study. In the student-patient interaction the paper document acquires specific affordances [35], as an interactional resource that both empowers and restricts action. The assessment form enables the nurse preceptor to demonstrate how a professional elicits and explores the patients' concerns in history-taking. It helps the patient to regulate disclosure of information and display of affect that may impose a face-threat in the apprenticeship context. Seen from the students' perspective, it helps to control the elicitation of information that may be delicate for an inexperienced apprentice to handle. As can be seen, the admission document features in the interaction as a useful method that mediates institutionality and professional legitimacy. As demonstrated in the last excerpt, it provides a way for all three participants to construct a locally relevant student identity. In another vein, the methods provided by the tool in the student-patient interaction constrain and limit the students' forms of action in the practice of history-taking. Heath [19, pages 161-62] discusses the physician's use of technology from various perspectives in a similar way. Using the records may even be seen as an interactional resource that the interlocutors can benefit from, he argues. Turning to the records and making notes may serve to display an appreciation of a stretch of talk. It could also be used to avoid embarrassment. When disclosing embarrassing information a patient may prefer the doctor to look away. As we have seen, Sarah and Lisa also benefit from similar forms of multifaceted artifact use. Affect displays and imposition of risk of losing face and allowing a talkative patient to control the interaction (cf. [5]) were artfully managed through the manipulation of the assessment form.

Interpreted within a Neo-Vygotskian framework [3032], this conflict between constraints and affordances provided by the tool is evidenced in Sarah's feedback talk with the nurse preceptor. Here, she expresses most convincingly the difficulties she sensed when the patient told her about his cancer diagnosis. As noted earlier, students are not prepared to elicit the patient's concerns [23]. The student's strategy of taking refuge in the assessment sheet (see Excerpt 1) certainly enabled her to cope with the situation, but it obviously leaves behind a strong feeling of frustration and inadequacy.

In the light of the knowledge provided by these data, the tool use in the third and last excerpt features as a most effective and creative strategy for mastering and bridging similar conflicts related to the paper work. A core question raised in the introduction to this study was what discourse strategies the patient will use when he/she is exposed to an inexperienced student. Staging the talk activity as an exercise and a training situation may facilitate the accomplishment of the interview both for the student and for the patient. Using the paperwork as a tool is an institutionally relevant and artful way of managing this work. Unlike the medical students in Thomassen's [24] study of role plays, Lisa (see Excerpt 3) displays willingness to negotiate multilayered frames in an explicit manner. She aligns with the patient by asking the 
nurse preceptor for assistance with the documentation. This is an effective strategy for coping with a complex situation, where she has to act as a professional, even though she does not have the legal right to do the same job as a nurse, for example, to document patients' care needs. In this respect she may benefit from being positioned as a student and not having to sustain a role as a professional at any cost. The patient, on the other hand, may benefit from adopting the role of helper when exposed to a training situation in which she cannot fully act out the role of patient. As can be seen in both Excerpts 1 and 3, the patient's discoursal strategy (listing previous treatments) helps the student to fill in the boxes on the assessment form.

As discussed in several places in the literature (e.g., [15, page 29], [36, page 347]), it is through the ways in which artifacts are used and seen that they gain a specific sense and relevance from within the course of action. To deal with this practical, indigenous use of the artifact warrants detailed attention to interactional processes and participation framework (cf. $[9,19,41]$. Bodily conduct and the material environment play a crucial part in the production of social action (e.g., $[26,28,41]$. As the close scrutiny of the elaborated turns demonstrated, the patient and the student build through embodied stance (gaze direction, facial expression, bodily movement, and manipulation of the artifact) a public field for mutual orientation to the acts of reading and writing. For instance, in Excerpt 3, we have seen in the multiparty exchange generated by Lisa's attention to the paper document (lines 23-28), how the student and the patient mutually orient to the nurse preceptor and use the paper document as a method for talking about the activity as an exercise. It is within this course of action that the artifact gains a specific relevance. The student's thinking aloud, while attending to the paperwork and searching for the next topic in the list of keywords, makes relevant the patient's metacomment on the writing and her orientation to the nurse preceptor. Here the student's paper work is turned into a public and socially distributed process embedded within a material world. As we have seen, the contextual frame created by the patient's embodied stance plays a crucial role for the organization of this participation framework that is a multiparty, cooperative work. The staging of the talk activity as a training situation is achieved in collaboration between the participants through the simultaneous deployment of different multimodal resources and through display of mutual orientation to the form-filling task. That is to say, the patient and the student create a public focus for the organization of attention to the paperwork that gives relevance to the nurse preceptor's forms of alignment (acknowledgement token and laughter, see Excerpt 3, line 26).

Both students follow closely and strictly the order of keywords as they appear on the assessment form. This is in a Vygotskyan sense a simple act of regulated problem solving with the help of an external means [29]. When they use the template tool they reduce a complex task to a series of concrete and simple procedures. As demonstrated, for both the students and the patients filling in the boxes on the proforma is the main focus of the activity. Or to put it another way, they fill in the form together. This is the participants' way of appropriating the tool provided to them by the sociocultural setting. They make it to their own and integrate it with their activities.

If we rethink artifacts dialogically [36], they are not just physical, external objects that have in themselves a preordained power. They become artifacts inscribed with affordances, meaning potentials, when they are actually used. Therefore, they cannot be conceptualized in isolation from their human users. When the students appropriate the assessment form, they attend to these opportunities for use in their special ways. As demonstrated, in interaction with the patients, they deploy and understand these affordances which in fact are relational phenomena. Even though the students do not use the assessment form in line with the ideology of patient centredness underlying the assessment framework, they deploy it creatively and in circumstantially relevant ways. The nurse preceptor's practices we saw in Excerpt 2 may also in a sense be said to rely on artifactuse. Her demonstration of the discourse practices of expert nursing care is supported by the use of the assessment form in the student-patient interaction.

The present study may provide grounds for considerations regarding implications of ward-level practices for students' socialization into professional activities, more specifically skills in performing health assessments. As noted by Candlin $[4,5]$, a trusting relationship is a prerequisite for encouraging the patient to disclose important information. It may be that the formal assessment interview does not help students to achieve this goal. The first-year student has not the required knowledge, the "habitus" [6], about health care environments to grasp the intentions underlying the empirically based assessment framework. Therefore, the socioculturally shaped keywords on the assessment form charged with sets of values may not aid students in producing coherent discourse rich in assessment data. As can be seen from the analysis in the present study, the students benefit from the paper document as an interactional resource that facilitates the movement through the list of questions and helps them to accomplish the task. It could also be argued that the students use the form the way they do since there is no instruction accompanying the form which states how it should be deployed.

The discussion above raises questions about how the assessment framework can best be utilized to help the students to achieve the course objectives. In Sweden the assessment interview is widely used at ward level as a training situation for first-year students. The formal assessment interview is only one of several ways of gathering information about the patient's care needs. A nurse needs to perform both formal and informal ongoing health assessments. The informal health assessment embedded in the care work may be a more feasible environment for the student's socialization. The ongoing process of assessing and planning patients' care needs may provide opportunities for the nurse preceptor to guide the student into talking about assessment topics that are meaningful and important for the patient. Focussing on a few assessment topics at a time can be done without paperwork, and it may be a more fruitful way of 
appropriating the framework than running through a list of a range of health care terms without understanding the meaning behind them. Students have to learn to use the artifact in a reflective way. To use a quote from Wertsch [32, page 29], they will otherwise run the risk of becoming "unreflective, if not ignorant, consumers of a cultural tool".

\section{Transcription Key}

\begin{tabular}{|c|c|}
\hline & Extension of preceding sound \\
\hline Underlining: & The word is stressed \\
\hline$=:$ & $\begin{array}{l}\text { An utterance is immediately latched to a } \\
\text { previous one, without any intervening } \\
\text { silence (latching) }\end{array}$ \\
\hline ow-: & Disrupted speech \\
\hline & Translation into English \\
\hline & $\begin{array}{l}\text { Separate left square brackets, one above the } \\
\text { other in two successive lines with utterances } \\
\text { by different speakers, indicate a point of } \\
\text { overlap onset }\end{array}$ \\
\hline$(($ nods $)):$ & $\begin{array}{l}\text { Material within double parenthesis }(()) \\
\text { marks comments on how something is said } \\
\text { or what happens in the context }\end{array}$ \\
\hline 1,6): & $\begin{array}{l}\text { Numbers in parentheses indicate elapsed } \\
\text { time in silence by tenth of seconds, so 1,6 is a } \\
\text { pause of one second and six tenths of a } \\
\text { second }\end{array}$ \\
\hline & $\begin{array}{l}\text { Micropause (a tiny gap within or between } \\
\text { utterances) }\end{array}$ \\
\hline$(\mathrm{xxx}):$ & Denotes undecipherable talk \\
\hline ( ): & $\begin{array}{l}\text { Means that the transcriber is uncertain about } \\
\text { the correct transcription }\end{array}$ \\
\hline 10 & $\begin{array}{l}\text { The degree signs indicate that the talk } \\
\text { between participants is markedly softer or } \\
\text { quieter than the adjacent talk }\end{array}$ \\
\hline he he: & Indicates laughter \\
\hline & Rising intonation. \\
\hline
\end{tabular}

\section{References}

[1] J. Latimer, The Conduct of Care, Blackwell Science, Oxford, UK, 2000.

[2] P. Sully and J. Dallas, Essential Communication Skills for Nursing, Elsevier Mosby, Edinburgh, UK, 2005.

[3] M. Ehnfors, A. Ehrenberg, and I. Thorell-Ekstrand, The VIPSBook: On an Empirically Based Template for Documentation of Nursing Care in the Patient Record, Vårdförbundet, Stockholm, Sweden, 2000.

[4] S. Candlin, Therapeutic Communication: A Lifespan Approach, Pearson Education Australia, New South Wales, Australia, 2008.

[5] S. Candlin, "Taking risks: an indicator of expertise?” Research on Language and Social Interaction, vol. 35, no. 2, pp. 173-193, 2002.

[6] P. Bourdieu, Language and Symbolic Power, Polity, Cambridge, UK, 1991.

[7] C. Goodwin, "Professional vision," American Anthropologist, vol. 96, no. 3, pp. 606-633, 1994.

[8] C. Goodwin and M. Goodwin, "Seeing as a situated activity: formulating planes," in Cognition and Communication at
Work, D. Middleton and Y. Engeström, Eds., pp. 61-95, Cambridge University Press, Cambridge, UK, 1996.

[9] J. Hindmarsh and C. Heath, "Sharing the tools of the trade: the interactional constitution of workplace objects," Journal of Contemporary Ethnography, vol. 29, no. 5, pp. 523-562, 2000.

[10] C. Heath and P. Luff, Technology in Action, Cambridge University Press, Cambridge, UK, 2000.

[11] L. Mondada, "Videorecordings as the reflexive preservation and configuration of phenomenal features for analysis," in Videoanalysis, H. Knoblauch, J. Raab, H.-G. Soeffner, and B. Schnettler, Eds., pp. 51-58, Lang, Bern, Switzerland, 2006.

[12] M. Broth, "Analyse de l'interaction à la télévision," Moderna Språk, vol. 97, no. 2, pp. 193-201, 2003.

[13] C. Heath, P. Luff, and M. Sanchez Svensson, "Technology and medical practice," Sociology of Health \& Illness, vol. 25, pp. 7596, 2003.

[14] A. Pilnick, J. Hindmarsh, and V. Teas Gill, Communication in Healthcare Settings: Policy, Participation and New Technologies, Wiley-Blackwell, West Sussex, UK, 2010.

[15] C. Heath and J. Hindmarsh, "Analysing interaction: video, ethnography and situated conduct," in Qualitative Research in Practice, T. May, Ed., pp. 99-121, Sage Publications, London, UK, 2002.

[16] A. Jones, "Nurses talking to patients: exploring conversation analysis as a means of researching nurse-patient communication," International Journal of Nursing Studies, vol. 40, no. 6, pp. 609-618, 2003.

[17] A. Jones, "Putting practice into teaching: an exploratory study of nursing undergraduates' interpersonal skills and the effects of using empirical data as a teaching and learning resource," Journal of Clinical Nursing, vol. 16, no. 12, pp. 2297-2307, 2007.

[18] A. Jones, "Creating history: documents and patient participation in nurse-patient interviews," Sociology of Health \& Illness, vol. 31, no. 6, pp. 907-923, 2009.

[19] C. Heath, Body Movement and Speech in Medical Interaction, Cambridge University Press, Cambridge, UK, 1986.

[20] H. Eide and T. Eide, Communication in Healthcare. Relational Ethics, Cooperation and Conflictsolving, Studentlitteratur, Lund, Sweden, 1997.

[21] K. L. Becker, L. E. Rose, J. B. Berg, H. Park, and J. H. Shatzer, "The teaching effectiveness of standardized patients," Journal of Nursing Education, vol. 45, no. 4, pp. 103-111, 2006.

[22] M. H. Rosenzweig, K. Magdic, M. Beach, M. Clifton, and R. Arnold, "Patient communication simulation laboratory for students in an acute care nurse practitioner program," American Journal of Critical Care, vol. 17, no. 4, pp. 364-372, 2008.

[23] G. Thomassen, The double-barreled training talk: a study of talks between patients and students from nurse and physician education, Unpublished doctoral dissertation, Norwegian University of Technology and Science, Trondheim, Norway, 2005.

[24] G. Thomassen, "Te role of role-play: managing activity ambiguities in simulated doctor consultation in medical education," Communication \& Medicine, vol. 6, no. 1, pp. 8393, 2009.

[25] A. Jones, "Admitting hospital patients: a qualitative study of an everyday nursing task," Nursing Inquiry, vol. 14, no. 3, pp. 212-223, 2007.

[26] C. Goodwin, "Action and embodiment within situated human interaction," Journal of Pragmatics, vol. 32, no. 10, pp. 1489$1522,2000$.

[27] C. Goodwin, "Pointing as situated practice," in Pointing: Where Language, Culture and Cognition Meet, S. Kita, Ed., 
pp. 217-241, Lawrence Erlbaum Associates, Hillsdale, NJ, USA, 2003.

[28] A. Kendon, Conducting Interaction: Patterns of Behaviour in Focused Encounters, Cambridge University Press, Cambridge, UK, 1990.

[29] L. Vygotsky, Mind in Society. The Development of Higher Psychological Processes, Harvard University Press, Cambridge, Mass, USA, 1978.

[30] J. V. Wertsch, Voices of the Mind: A Sociocultural Approach to Mediated Action, Harvard University Press, Cambridge, Mass, USA, 1991.

[31] J. Wertsch, "A sociocultural approach to socially shared cognition," in Persectives on Socially Shared Cognition, L. B. Resnick, J. M. Levine, and S. D. Teasley, Eds., pp. 85-99, American Psychological Association, Washington, DC, USA, 1991.

[32] J. Wertsch, Mind as Action, Oxford University Press, New York, NY, USA, 1998.

[33] E. Hutchins, Cognition in the Wild, The MIT Press, Cambridge, Mass, USA, 1995.

[34] P. Thibault, "The interpersonal gateway to the meaning of mind: unifying the inter- an intraorganism perspective on language," in Continuing Discourse on Language: A Functional Perspective, R. Hasan, C. Mathiessen, and J. Webster, Eds., pp. 117-156, Equinox, London, UK, 2005.

[35] J. Gibson, The Ecological Approach to Visual Perception, Houghton-Mifflin, Boston, Mass, USA, 1979.

[36] P. Linell, Rethinking Language, Mind, and World Dialogically: Interactional and Contextual Theories of Human Sense-Making, Information Age Publishing, Charlotte, NC, USA, 2009.

[37] M. Holquist, Dialogism: Bakhtin and His World, Routledge, London, UK, 1990.

[38] R. Rommetveit, "On axiomatic features of a dialogical approach to language and mind," in The Dynamics of Dialogue, I. Markova and K. Foppa, Eds., pp. 83-104, Harvester Wheatsheaf, New York, NY, USA, 1990.

[39] H. Sacks, E. A. Schegloff, and G. Jefferson, "A simplest systematic for the organization of turn-taking for conversation," Language, vol. 50, no. 4, part 1, pp. 896-735, 1974.

[40] J. Sidnell, Conversation Analysis. An Introduction, WileyBlackwell, Singapore, 2009.

[41] C. Goodwin, "Participation, stance and affect in the organization of activities," Discourse \& Society, vol. 18, no. 1, pp. 53-73, 2007.

[42] J. Lave and E. Wenger, Situated Learning. Legitimate Peripheral Participation, Cambridge University Press, Cambridge, UK, 1991.

[43] G. Jansson, "Student supervision in hybrid contexts," Språk \& Stil, vol. 20, pp. 189-219, 2010.

[44] H. Bani-Shoraka, "When different worlds meet. Ethnographic fieldwork in a multilingual educational environment," Ethnography and Education. In press.

[45] G. Jansson, "Artifact-based interviews at a hospital ward," in Svenskans beskrivning 31. Förhandlingar vid Trettioförsta sammankomsten för svenskans beskrivning, A.-C. Edlund, Ed., Norstedts Akademiska Förlag, Stockholm, Sweden, May 2010.

[46] T. Stivers and J. Heritage, "Breaking the sequential mold: answering 'more than the question' during comprehensive history taking," Text, vol. 21, no. 1-2, pp. 151-185, 2001.

[47] E. Boyd and J. Heritage, "Taking the history: questioning during comprehensive history taking," in Communication in Medical Care: Interaction between Primary Care Physicians and Patients, J. Heritage and D. Maynard, Eds., pp. 151-180, Cambridge University Press, Cambridge, UK, 2006.
[48] E. Ochs and B. Schieffelin, "Language has a heart," Text, vol. 9, no. 1, pp. 7-25, 1989 .

[49] H. Sacks, "Everyone has to lie," in Sociocultural Dimensions of Language Use, M. Sanches and B. G. Blount, Eds., pp. 57-79, Academic Press, New York, NY, USA, 1975.

[50] G. Jefferson, "On "Trouble-premonitory" response to inquiry," Sociological Inquiry, vol. 50, no. 3-4, pp. 153-185, 1980.

[51] P. Linell, "Grammatical constructions in practices of talk," in Grammar and Conversation. Studies in Memoriam of Mats Eriksson, B. Nordberg, L. Keevalik Eriksson, K. Thelander, and M. Thelander, Eds., pp. 199-218, Department of Scandinavian Languages at Uppsala University, Uppsala, Sweden, 2003.

[52] N. Norén, A Family of Methods for Grammatical Construction and the Resolving of Local Communicative Projects, Linköping Studies in Arts and Science 405, Linköping University, Linköping, Sweden, 2007.

[53] M. Berg, "Practices of reading and writing: the constitutive role of the patient record in medical work," Sociology of Health \& Illness, vol. 18, no. 4, pp. 499-524, 1996.

[54] T. Stivers, "Stance, alignment, and affiliation during storytelling: when nodding is a token of affiliation," Research on Language \& Social Interaction, vol. 41, no. 1, pp. 31-57, 2008.

[55] G. Jefferson, "On stepwise transition from talk about a trouble to inappropriately next-positioned matters," in Structures of Social Action, J. M. Atkinson and J. Heritage, Eds., Cambridge University Press, Cambridge, UK, 1984. 


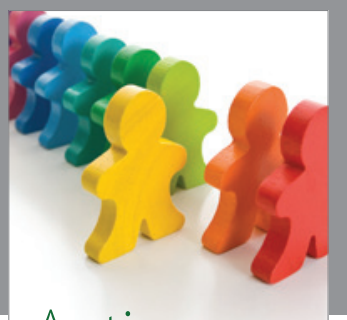

Autism

Research and Treatment
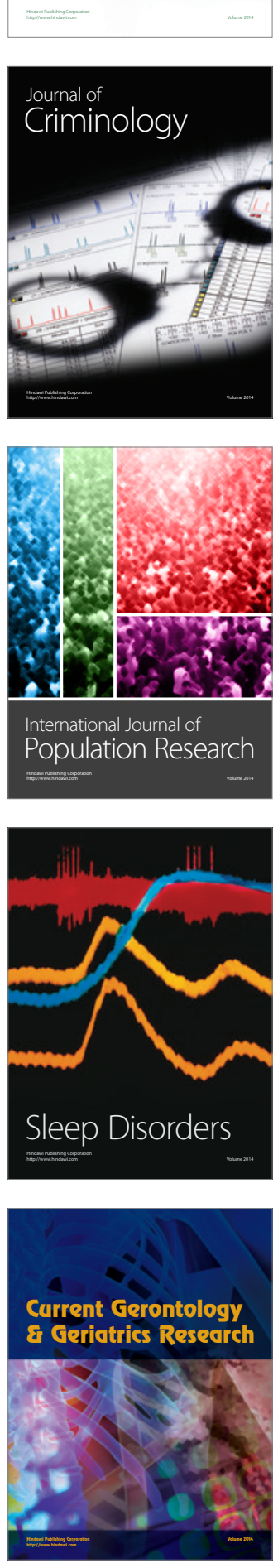
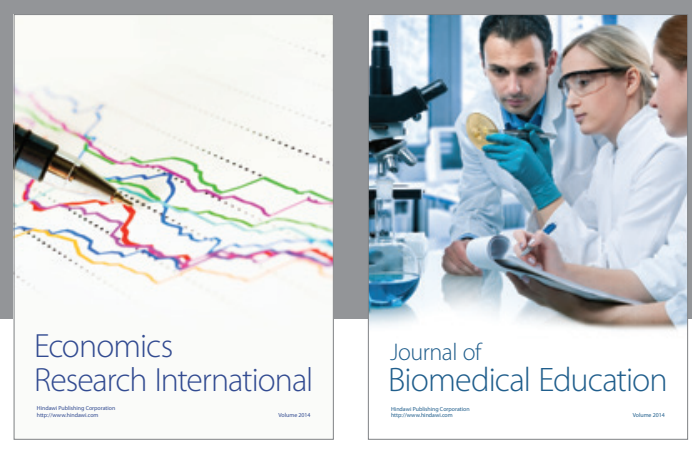

Journal of

Biomedical Education

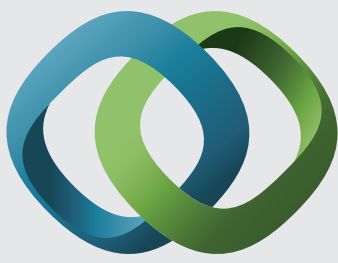

\section{Hindawi}

Submit your manuscripts at

http://www.hindawi.com
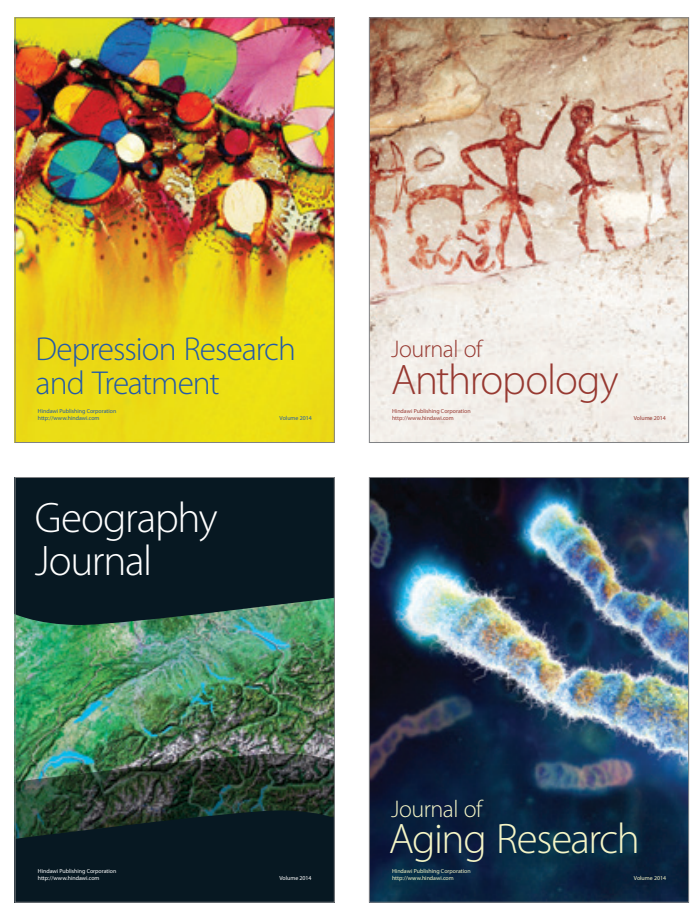

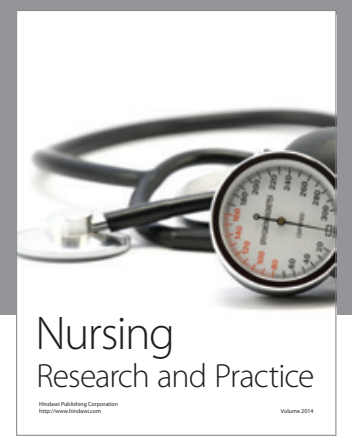

Nursing

Research and Practice

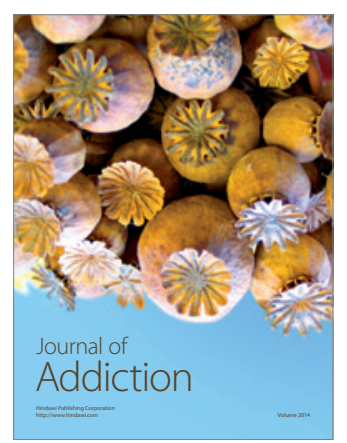

Child Development

Research

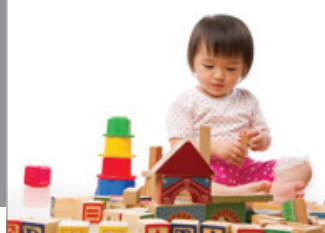

迥
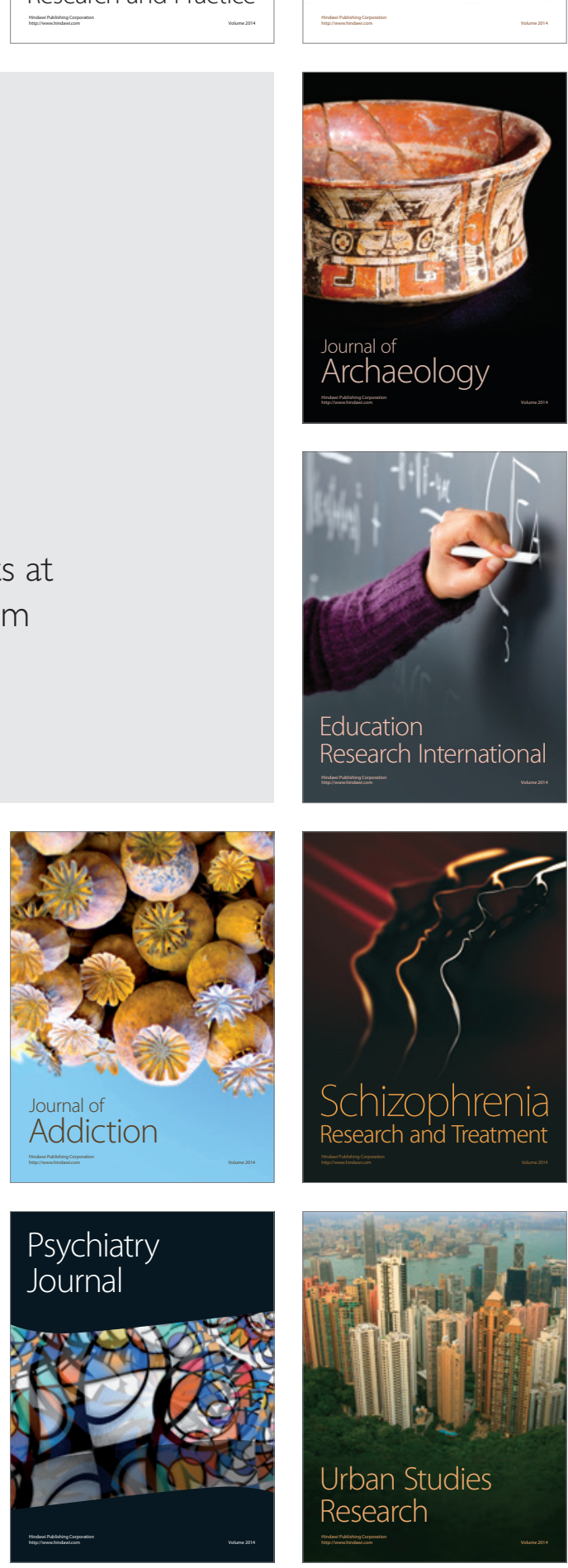